\title{
Population red blood cell folate concentrations for prevention of neural tube defects: bayesian model
}

\author{
@(థ) OPEN ACCESS
}

\author{
Krista S Crider geneticist ${ }^{1}$, Owen Devine statistician ${ }^{1}$, Ling Hao laboratorian ${ }^{23}$, Nicole F Dowling \\ associate director for science ${ }^{1}$, Song Li pediatrician ${ }^{4}$, Anne M Molloy professor ${ }^{5}$, Zhu Li retired \\ medical epidemiologist $^{2}$, Jianghui Zhu laboratorian ${ }^{26}$, Robert J Berry medical epidemiologist ${ }^{1}$
}

${ }^{1}$ National Center on Birth Defects and Developmental Disabilities, Centers for Disease Control and Prevention, Atlanta, GA 30333, USA; ${ }^{2} \mathrm{Peking}$ University Health Science Center, Peking University, Beijing, China; ${ }^{3}$ US Centers for Disease Control and Prevention, US Embassy, Beijing, China; ${ }^{4}$ Peking University Third Hospital, Beijing, China; ${ }^{5}$ School of Medicine, Trinity College, Dublin, Ireland; ${ }^{6}$ Division of Risk Assessment, China National Center for Food Safety Risk Assessment, Beijing, China

\begin{abstract}
Objective To determine an optimal population red blood cell (RBC) folate concentration for the prevention of neural tube birth defects.

Design Bayesian model.

Setting Data from two population based studies in China.

Participants 247831 participants in a prospective community intervention project in China (1993-95) to prevent neural tube defects with $400 \mu \mathrm{g} /$ day folic acid supplementation and 1194 participants in a population based randomized trial (2003-05) to evaluate the effect of folic acid supplementation on blood folate concentration among Chinese women of reproductive age.

Intervention Folic acid supplementation ( $400 \mu \mathrm{g} /$ day).

Main outcome measures Estimated RBC folate concentration at time of neural tube closure (day 28 of gestation) and risk of neural tube defects.

Results Risk of neural tube defects was high at the lowest estimated RBC folate concentrations (for example, 25.4 (95\% uncertainty interval 20.8 to 31.2 ) neural tube defects per 10000 births at $500 \mathrm{nmol} / \mathrm{L}$ ) and decreased as estimated RBC folate concentration increased. Risk of neural tube defects was substantially attenuated at estimated RBC folate concentrations above about $1000 \mathrm{nmol} / \mathrm{L}$ (for example, 6 neural tube defects per 10000 births at 1180 (1050 to 1340) nmol/L). The modeled dose-response relation was consistent with the existing literature. In addition, neural tube defect risk estimates developed using the proposed model and population level RBC information were consistent with the prevalence of neural tube defects in the US population before and after food fortification with folic acid.
\end{abstract}

Conclusions A threshold for "optimal" population RBC folate concentration for the prevention of neural tube defects could be defined (for example, approximately $1000 \mathrm{nmol} / \mathrm{L}$ ). Population based RBC folate concentrations, as a biomarker for risk of neural tube defects, can be used to facilitate evaluation of prevention programs as well as to identify subpopulations at elevated risk for a neural tube defect affected pregnancy due to folate insufficiency.

\section{Introduction}

Clinical trials, community intervention programs, and food fortification programs over the past decades have shown that maternal folic acid intake before and during early pregnancy reduces a woman's risk of having a pregnancy affected by a neural tube birth defect. ${ }^{1-3}$ Every year, an estimated 300000 or more pregnancies are affected by neural tube defects. ${ }^{4}$ To reduce the substantial morbidity, mortality, and cost of these devastating conditions, programs of staple food fortification with folic acid have been adopted and have resulted in prevention of neural tube defects in many countries (such as Chile, the United States, Canada, Costa Rica, and South Africa).$^{5-9}$ All public health recommendations in the United States for prevention of neural tube defects are based on suggested levels for dietary intake of folate/folic acid (for example, $400 \mu \mathrm{g} /$ day).${ }^{10}$ However, estimating natural intake of folate from food is difficult, expensive, and imprecise, as it requires large population based surveys that rely on self reported dietary recall. A reliable biomarker (such as red blood cell or serum folate concentrations) would be useful for evaluating the potential public health impact of prevention programs for neural tube defects. Existing definitions of clinical folate deficiency $(<340 \mathrm{nmol} / \mathrm{L}$ red blood cell folate concentrations and $<10 \mathrm{nmol} / \mathrm{L}$ serum folate concentrations $)^{11}$ are not based on folate sufficiency for the prevention of neural tube defects, so existing cut-off values are inappropriate for use in efforts to prevent neural tube defects. Folate sufficiency or optimal blood folate concentrations that 
are directly linked to risk of neural tube defects are needed and could be used as a benchmark to enhance the biomarker based monitoring of prevention efforts and as a tool for needs assessments of such efforts (for example, implementing or modifying fortification programs).

The exact mechanism by which maternal consumption of periconceptional folic acid prevents some neural tube defects ("folate sensitive" neural tube defects) remains uncertain. ${ }^{12-14}$ However, many studies have shown increases in both red blood cell and serum/plasma folate concentrations in response to increased folic acid intake ${ }^{15-23}$ (fig $1 \Downarrow$ ). Genetic variation in folate metabolism due to a single nucleotide polymorphism at the methylene tetrahydrofolate reductase (MTHFR) gene (667 $\mathrm{C}$ to $\mathrm{T}$ transition) has also been shown to be associated with reduced red blood cell folate concentrations for a given intake of folic acid (the synthetic form of folate used in foods and supplements $)^{24}$ and with increased risk of neural tube defects across studies. ${ }^{25} 26$

Although the effects of folic acid intake on risks of neural tube defects are well established, ${ }^{125-7} 27$ only one study has directly described differences in the risk of having a child with a neural tube defect across a range of maternal red blood cell folate concentrations. ${ }^{28} \mathrm{~A}$ single case-control study in Ireland (1986-90) assessed the association between maternal red blood cell folate concentration measured during early pregnancy (median gestational age 15 weeks; 84 cases, 266 controls) and subsequent risk of neural tube defects. ${ }^{28}$ In this study, Daly and colleagues observed a very high risk of neural tube defects at lower concentrations of red blood cell folate $(<340 \mathrm{nmol} / \mathrm{L}$ : risk of 66 per 10000 births) and substantially mitigated risk at concentrations above a cut-off concentration of $906 \mathrm{nmol} / \mathrm{L}$ ( 8 neural tube defects per 10000 births; mean $1292 \mathrm{nmol} / \mathrm{L}){ }^{28}$ Whether findings from this single study in Ireland are generalizable to other populations with different micronutrient intakes or racial/ethnic backgrounds is unclear. Moreover, as 8 neural tube defects per 10000 births could still be considered a moderately high risk population, additional data above the $906 \mathrm{nmol} / \mathrm{L}$ cut-off concentration for red blood cell folate are needed to examine the possibility of further risk reductions at higher red blood cell folate concentrations.

To investigate this question, we used existing data sources to assess the potential association between red blood cell folate concentrations at the time of neural tube closure (embryologic day 28) and risk of neural tube defects among participants in the Community Intervention Project (China 1993-95; $n=247$ 831). ${ }^{15} 2429-31$ We then compared the estimated association developed in this analysis with that observed in the Irish population reported by Daly and colleagues. ${ }^{28} \mathrm{We}$ also used the modeled association to predict risk of neural tube defects in the US population before and after fortification from published population based distributions of red blood cell folate concentrations. Finally, we used the results of our analysis to derive candidate red blood cell folate concentrations for the prevention of folate sensitive neural tube defects.

\section{Methods}

\section{Study populations}

Two study populations contributed data to this study (supplementary table A): the Community Intervention Project and the Folic Acid Dosing Trial. The Community Intervention Project was a population based cohort study of a public health campaign conducted in northern (Hebei Province) and southern (Zhejiang and Jiangsu Provinces) regions of China from 1993 through 1995. Women were encouraged to consume $400 \mu \mathrm{g}$ of folic acid a day when planning pregnancy through the end of the first trimester; the results of an analysis comparing the risk of neural tube defects in women in this study who took folic acid supplements with that in those who did not have been previously described. ${ }^{1}$ In short, all women who were planning a pregnancy or undergoing mandatory premarital examinations were enrolled in a pregnancy monitoring system and were asked to purchase bottles of folic acid supplements (31 pills, $400 \mu \mathrm{g}$ ) and consume one folic acid supplement a day through the end of the first trimester. ${ }^{1}$ Health workers recorded the dates that the women started and stopped taking folic acid supplements, the number of pills remaining in the bottles at the end of each month as a measure of pill taking compliance, and the dates of the women's menstrual periods. ${ }^{1}$ Infants and fetuses with all types of neural tube defects (that is, anencephaly, craniorachischisis, iniencephaly, spina bifida, and encephalocele) were ascertained through a birth defects surveillance system that collected information on all live and stillborn infants ( $>20$ weeks' gestation) and those pregnancies terminated at any gestation after the detection of a birth defect.

In the analyses presented here, we included women if enough information was collected to enable the estimation of red blood cell folate concentration at the time of neural tube closure (embryologic day 28, calculated by firstly adding 14 days to the date of the start of the last menstrual period recorded by the health workers (estimated date of conception) plus another 28 days for completion of neural tube closure (supplementary table A). We included women who fulfilled the following criteria: the woman became pregnant during the study period; the outcome of the pregnancy was known (including still births and pregnancy terminations for birth defects); folic acid supplement taking status was known (yes $v$ no); and, for those who took folic acid supplements, the start and stop dates were recorded. Women who started taking pills but stopped before becoming pregnant were excluded from the analyses owing to insufficient data for estimation of red blood cell folate concentrations at the time of neural tube closure (supplementary figure A).

The second study, the Folic Acid Dosing Trial randomized trial (registered at clinicaltrials.gov: NCT00207558), was conducted in the northern Chinese province of Hebei from 2003 to $2005 .^{15} 24$ Requirements for participation in the Folic Acid Dosing Trial included to not be pregnant or breastfeeding and to have an intrauterine device for contraception; to have no plans to become pregnant within nine months of recruitment into the trial; to live in the township; to have a child aged 2-4 years; to have had no folic acid supplement use within the previous three months; and to have no current prescription drug use. ${ }^{15}{ }^{24}$ Foods fortified with folic acid were not available in China at the time, so study participants were not exposed to dietary sources of folic acid. Enrolled women were excluded from further participation and were referred for medical treatment if they were either vitamin $\mathrm{B}_{12}$ deficient (plasma vitamin $\mathrm{B}_{12}<148 \mathrm{pmol} / \mathrm{L}$ ) or anemic (hemoglobin $<120 \mathrm{~g} / \mathrm{L}$ ); however, baseline folate concentrations and MTHFR genotypes $(\mathrm{n}=1194)$ were measured for all enrolled women (supplementary figure B). ${ }^{1524}$ Randomized participants were given weekly blister packs with four pills a day (folic acid or placebo as appropriate) and assigned to dosage regimens of $100 \mu \mathrm{g} / \mathrm{day}, 400 \mu \mathrm{g} / \mathrm{day}, 4000 \mu \mathrm{g} / \mathrm{day}$, or $4000 \mu \mathrm{g} /$ week. Red blood cell folate concentrations and MTHFR genotyping was performed on all available samples, as previously reported. ${ }^{15} 2432$ Fasting blood samples were collected at enrollment and after one, three, and six months of supplementation. In the analysis presented here, we used information only from Folic Acid Dosing Trial participants who consumed $400 \mu \mathrm{g} /$ day folic acid (either $400 \mu \mathrm{g}$ once a day or $100 \mu \mathrm{g}$ four times a day; $\mathrm{n}=323$ ) 
and had MTHFR genotype information (supplementary figure B)..$^{15} 24$

\section{General modeling strategy}

The goal of this analysis was to estimate the association between a mother's red blood cell folate concentration at the time of her fetus's neural tube closure and the risk of a neural tube defect. The primary data source for the analysis was the Community Intervention Project, a public health campaign conducted in China in the northern province of Hebei and the southern provinces of Zhejiang and Jiangsu to reduce the risk of neural tube defects by encouraging daily maternal periconceptional consumption of $400 \mu \mathrm{g}$ of folic acid. ${ }^{1}$ This study provided information on the length of time that participants consumed daily folic acid supplements before pregnancy and the neural tube defect outcomes among 228456 live births and fetal deaths, but measurements of red blood cell folate concentration at the time of neural tube closure and the mother's MTHFR genotype were not collected. However, data from one daily dosage of the Folic Acid Dosing Trial, which was conducted on a sample of women from the northern province of Hebei, provided information on both red blood cell folate concentrations at zero, one, three, and six months of $400 \mu \mathrm{g} /$ day of folic acid supplementation and MTHFR genotype (supplementary figure C). ${ }^{24}$ Using data from the Folic Acid Dosing Trial, we modeled the association between the length of time women consumed folic acid and their resulting red blood cell folate concentrations, including the effect of genotype on that association. We then used this model to estimate red blood cell folate concentrations for Community Intervention Project participants on the basis of their reported pill consumption, enabling an evaluation of the association between the estimates of red blood cell folate concentrations and risk of neural tube defects.

The fact that MTHFR genotype was not determined for Community Intervention Project participants and that genotype can significantly affect the estimation of red blood cell folate concentrations necessitated development of additional models to estimate the distribution of genotypes among the Community Intervention Project participants. We adjusted baseline red blood cell folate concentrations for known differences in red blood cell folate concentrations and MTHFR genotype distributions in northern and southern China (supplementary table B). ${ }^{29-31}$ As a result, our analysis of the association between red blood cell folate concentration and risk of neural tube defects among the Community Intervention Project study population required development of three component models (fig $2 \Downarrow$ ). (1) A red blood cell folate concentration model estimating red blood cell folate concentration at the time of neural tube closure in Community Intervention Project participants on the basis of red blood cell folate concentration in northern and southern provinces adjusted for consumption of $400 \mu \mathrm{g}$ of folic acid a day (if consumed) based on Folic Acid Dosing Trial dose-response to $400 \mu \mathrm{g} /$ day folic acid supplementation. (2) A genotype model for estimating the distribution of MTHFR alleles among Community Intervention Project participants. (3) A risk model relating a mother's estimated red blood cell folate concentration at the time of her fetus's neural tube closure and risk of neural tube defect.

We used a Bayesian approach to update prior assumptions on the parameters of these models by using the observed information on time consuming folic acid supplements and neural tube defect outcomes available in the Community Intervention Project data. Details on the models, the prior assumptions on the parameters of the models, and the bayesian fitting algorithm are given in the statistical appendix.

\section{Prediction of neural tube defect risk from published red blood cell folate concentration distributions in US population}

We applied the model developed as described above to predict risk of neural tube defects on the basis of published estimates of the distribution of red blood cell folate concentrations among US women before and after folic acid fortification as well as among pregnant women. ${ }^{33}{ }^{34}$ We used published data from the National Health and Nutrition Examination Survey (NHANES). ${ }^{33}{ }^{34}$ The red blood cell folate concentrations presented by Pfeiffer et al 2012 and Branum et al 2013 were generated by a microbiological assay (calibrated with 5 , methylTHF) that was normalized to the microbiological assay used in the Folic Acid Dosing Trial and the Daly study (calibrated with folic acid) using the equation: NHANES red blood cell folate $(\mathrm{nmol} / \mathrm{L})=($ Daly and Folic Acid Dosing Trial red blood cell folate $(\mathrm{nmol} / \mathrm{L}) \times 0.7876)+34.2802(\mathrm{nmol} / \mathrm{L})$ (personal communication from the data presented in Pfeiffer et al 2011). ${ }^{33-35}$ We normalized the pre-fortification folate concentration data to the microbiological assay in the original manuscript ${ }^{33}$; we then converted them by using the same conversion equation to approximate a match to the Daly et al data. ${ }^{28}$ We used the adjusted published distributions of red blood cell folate concentration to generate a modeled population with a similar distribution of red blood cell folate concentration, ${ }^{33}{ }^{34}$ and then we used the modeled associations in the Chinese data to predict the risk in that modeled US population. Addition details are provided in the statistical appendix.

\section{Results}

The region specific distribution of months consuming folic acid supplements for Community Intervention Project participants are shown in supplementary table C. In both regions, a large proportion of the participants did not take any supplements (overall 60\%). Among those who did take supplements, months on pills before neural tube closure were fairly evenly distributed across one to six months. We developed estimates for the distribution of red blood cell folate concentration at neural tube closure (day 28 of gestation) among the 228456 Community Intervention Project study participants by using the posterior estimates of the parameters of the concentration model (supplementary table D). Most (54.4\%) of the Community Intervention Project participants had estimated red blood cell folate concentrations between 800 and $900 \mathrm{nmol} / \mathrm{L}$; few had estimated red blood cell folate concentrations less than 500 $\mathrm{nmol} / \mathrm{L}(6.9 \%)$ or more than $1500 \mathrm{nmol} / \mathrm{L}(5.2 \%)$

(supplementary table E). Therefore, we assumed the modeled association between red blood cell folate and risk of neural tube defects to be most reliable in a range of estimated red blood cell folate concentrations between about 500 and $1500 \mathrm{nmol} / \mathrm{L}$.

We used the posterior estimates of the parameters of the risk model (supplementary table F) to estimate the population level risk of a neural tube defect at specified concentrations of red blood cell folate (fig $3 \Downarrow$, solid blue lines). A result of this estimation process is the ability to use the $95 \%$ uncertainty intervals surrounding the risk estimates to identify a range of red blood cell folate concentrations associated with specified levels of risk of neural tube defects (fig $3 \Downarrow$ dashed blue lines). Using this approach, we estimated that the risk of a neural tube defect affected pregnancy was highest among women with lower estimated red blood cell folate concentrations and was substantially attenuated among those with higher red blood cell folate concentrations. For example, a risk of 20 neural tube defects per 10000 births was associated with an estimated red 
blood cell folate concentration of 580 (95\% uncertainty interval 510 to 640$) \mathrm{nmol} / \mathrm{L}$, whereas a much lower neural tube defect risk of 6 per 10000 was associated with an estimated red blood cell folate concentration of 1180 (1050 to 1340) nmol/L (table $1 \Downarrow)$. We also used the model to estimate the population level risk of neural tube defects at specific red blood cell folate concentrations (table $2 \Downarrow$ ). At a red blood cell folate concentration of $500 \mathrm{nmol} / \mathrm{L}$ the estimated risk of a neural tube defect was 25.4 (20.8 to 31.2) per 10000 , whereas at a red blood cell folate concentration of $1200 \mathrm{nmol} / \mathrm{L}$ the estimated risk was more than fourfold lower at 5.8 (4.6 to 7.1) per 10000 (table $2 \Downarrow$ ).

We also used posterior estimates of the parameters of the risk model to estimate the risk ratio for a neural tube defect among MTHFR genotypes. Using this model, we estimated that the $M T H F R$ TT genotype confers increased risk relative to both the CC (TT $v$ CC: relative risk 1.49, 95\% uncertainty interval 1.33 to 1.70 ) and CT (TT $v$ CT: $1.28,1.17$ to 1.39 ) genotypes. In addition, we estimated that the relative risk for a neural tube defect is elevated for the $\mathrm{CT}$ genotype relative to $\mathrm{CC}$ genotype (CT $v$ CC: $1.17,1.06$ to 1.29 ).

Our estimates of the association of red blood cell folate concentration with risk of neural tube defects are consistent with those observed by Daly and colleagues (fig $3 \Downarrow$ ). ${ }^{28}$ The posterior estimate of the coefficient of the logistic model relating the odds of a neural tube defect to the natural logarithm of red blood cell concentration (supplementary table F) was -1.7 ( -2.01 to -1.38 ). Estimates of risk of neural tube defect among US women calculated using published red blood cell folate concentrations as model inputs are shown in supplementary table G. ${ }^{33}{ }^{34}$ We estimated that the risk of neural tube defects in the fifth centile of red blood cell folate concentrations among all US women dropped considerably from an estimated 35.9 (28.1 to 46.2) neural tube defects per 10000 births before fortification (1988-94) to 14.6 (12.4 to17.0) neural tube defects per 10000 births after fortification (2005-10). On the basis of the distributions of red blood cell folate concentration from Pfeiffer et al,,$^{33}$ we estimated the population level US pre-fortification prevalence of neural tube defects to be in the range of 10.1 to 16.4 per 10000 births and the post-fortification prevalence to be in the range of 4.2 to 7.8 per 10000 births (fig $4 \Downarrow$ ). Among pregnant women (all trimesters) after fortification, moderately increased estimates of risk of neural tube defects were found below the 10th centile of non-supplement using pregnant women (estimated risk of 12.9 (11.0 to 15.1) neural tube defects per 10000 births).

\section{Discussion}

We generated estimates of risk of neural tube defects for a full range of red blood cell folate concentrations by using information in the published literature and individual level data from two studies conducted in China, a community intervention project and a randomized clinical trial of folic acid

supplementation. The estimated risk of neural tube defects was highest at lower red blood cell folate concentrations (25.4 (95\% uncertainty interval 20.8 to 31.2 ) neural tube defects per 10000 births at $500 \mathrm{nmol} / \mathrm{L}$ ). The risk was substantially attenuated at estimated red blood cell folate concentrations above 1000 nmol/L (for example, 6 neural tube defects per 10000 births at $1180(1050$ to 1340$) \mathrm{nmol} / \mathrm{L})$. Our results indicate that a red blood cell folate concentration of roughly $1000-1300 \mathrm{nmol} / \mathrm{L}$ might achieve optimal prevention of folate sensitive neural tube defects, with a resulting overall risk of neural tube defects of about 6 per 10000 . This range could be useful in the development and monitoring of folic acid fortification programs.

\section{Association of neural tube defects and red blood cell folate concentrations in China compared with Ireland}

The modeled associations presented in our study were highly consistent with the only study in which the association between measured red blood cell folate concentrations in pregnancy and risk of neural tube defects was directly assessed (fig $3 \Downarrow$ ). ${ }^{28}$ Daly et al's study had considerable differences from our project, ${ }^{28}$ including different racial groups, different typical diets and corresponding micronutrient intake, a natural diet with no folic acid intervention compared with the presence of an intervention with folic acid, directly measured data compared with a combination of directly measured data and modeled data, and samples drawn at about 15 weeks of pregnancy compared with modeled at day 28 of gestation. The fact that the two distinct studies produced comparable estimates of the associations between risk of neural tube defects and red blood cell folate concentration is an indicator of the potential importance of red blood cell folate concentration as a biomarker for risk of neural tube defect and provides evidence for the generalizability of this biomarker across these different populations.

\section{Effect of MTHFR genotype}

MTHFR 677 genotype has previously been shown to be important in determining red blood cell folate concentrations in response to specific doses of folic acid supplementation and is associated with risk of neural tube defects across studies. ${ }^{24} 2526$ Similarly to the published meta-analyses, ${ }^{25}{ }^{26}$ we estimated the relative risk of a neural tube defect affected pregnancy to be elevated for the MTHFR TT genotype compared with CC (relative risk $1.49,95 \%$ uncertainty interval 1.33 to 1.70 ) and for TT compared with CT (1.28, 1.17 to 1.39$)$ genotypes. The approach used in our analysis is based on the assumption that the effect of the MTHFR T allele on risk of neural tube defect is associated with its role in causing a decrease in folate concentrations. Because of our reliance on the use of imputed estimates of red blood cell folate concentration, we did not deem it feasible to assess any additional effect of MTHFR on risk of neural tube defect beyond this. However, increased risk of neural tube defect associated with the MTHFR TT genotype would be predicted to be greatest in populations with low folate intake (for example, $\sim 200 \mathrm{nmol} / \mathrm{L}$ decrease in red blood cell folate concentration from 700 to $500 \mathrm{nmol} / \mathrm{L} \approx$ increase from 14.4 to 25.5 neural tube defects per 10000 births compared with decrease from 1400 to $1200 \mathrm{nmol} / \mathrm{L} \approx$ increase from 4.5 to 5.8 neural tube defects per 10000 births). This is consistent with other studies of MTHFR that show the strongest effects in settings with low folate intake. ${ }^{36}$ Similarly, increasing folate (natural and/or folic acid) intake resulting in increases in red blood cell folate concentrations could have the greatest effect on reducing the number of neural tube defect affected pregnancies among women with the lowest baseline red blood cell folate concentrations. Although folate intake and MTHFR genotype are clearly associated with the risk of neural tube defects, the consistency of our modeled estimates with those observed by Daly et al suggests that the observed increased risk of neural tube defects associated with low folate intake, MTHFR genotype, or both might be due to their effects on lowering blood folate concentrations. In populations with a high percentage of the population with the MTHFR T allele, additional folate (or folic acid) intake would be needed to achieve a specific red blood cell folate concentration (such as $1000 \mathrm{nmol} / \mathrm{L}$ ); however, similar risks of neural tube defects would be expected for two populations with similar distributions of red blood cell folate concentrations regardless of genotype. 
If this is the case, measured red blood cell folate concentrations can potentially be used to predict risk of neural tube defects in populations without additional information on folate/folic acid intake or MTHFR genotype as was shown in our analysis (fig $4 \Downarrow)$.

\section{Strengths and limitations}

A limitation of our analysis is the lack of measured red blood cell folate concentrations and MTHFR genotyping among Community Intervention Project study participants. However, we were able to use an estimate of the association between folic acid intake and subsequent red blood cell folate concentrations observed in an independent Chinese cohort in our analysis. Several studies have shown similar rates of increase in red blood cell folate concentrations for folic acid supplementation at about $400 \mu \mathrm{g} /$ day (supplementary figure F). This observed similarity increases our confidence in applying the association between folic acid intake and resulting red blood cell folate concentrations from the northern Chinese study population to the southern Chinese study population. However, we acknowledge that the use of the Folic Acid Dosing Trial based model relating intake and red blood cell folate concentration in the Community Intervention Project analysis and the use of published literature for the southern region's baseline red blood cell folate concentrations and genotype frequencies rely on unverifiable, although reasonable, assumptions. The bayesian modeling approach used in this analysis gave us a mechanism to incorporate uncertainty associated with these assumptions into the final estimates.

Another limitation of this analysis is that we applied estimated red blood cell folate concentrations from women who were not pregnant (Folic Acid Dosing Trial) to those who were 28 days pregnant (Community Intervention Project). This assumes that red blood cell folate concentrations do not change substantially during the first 28 days after conception. Without supplementation, folate concentrations have been reported to fall as pregnancy advances past the first trimester, with substantial reductions by the third trimester, ${ }^{37}{ }^{38}$ presumably due to hemodilution. Whether changes in blood folate concentrations or folic acid metabolism occur in the first 28 days compared with the immediate pre-pregnancy time period is not known. The similarity between our analysis and the Daly et al analysis (mean gestational age 15 weeks) ${ }^{28}$ suggests that no dramatic shifts occur. As we intend the model to be used to predict risk of neural tube defects in a population with red blood cell folate concentration collected from non-pregnant women, the fact that our findings and those of Daly et al are in such close agreement is reassuring. ${ }^{28}$

A major strength of our study is the large sample size of the observed data on which the model's estimates were based: 228 456 births and 250 neural tube defects. All subtypes of neural tube defects were included in the Community Intervention Project and in Daly et al, ${ }^{128}$ allowing for comparison of the overall rates of neural tube defects. The inclusion of all neural tube defects, as well as neural tube defects resulting in pregnancy loss and terminations, is important when evaluating the presented estimates of red blood cell folate concentration and risk of neural tube defects and comparing the prevalences of neural tube defects with those of other populations. The availability of high quality compliance data for the folic acid supplement taking history of participating women allowed adjustment of the estimated red blood cell folate concentrations. Furthermore, our assessment of alternative data inputs (see statistical appendix) indicated that the assumptions about the risk model parameters and the adequacy of the assumed concentration model had a marginal effect on the estimates presented in this analysis. The estimates derived in our modeling approach, which used no direct information from results of Daly et al, were consistent with the findings from that Irish cohort, thereby providing independent support for our general modeling assumptions and supporting the generalizability of our estimated results, at least among the populations being compared. Finally, we were able to use published red blood cell folate concentrations from the US population before and after fortification to predict risks of neural tube defects consistent with published prevalence estimates. Taken together, this suggests that distributions of red blood cell folate concentration can be used to predict the risk of folate sensitive neural tube defects in some populations and may be useful in establishing the need for and success of folic acid intervention programs.

\section{Implications for neural tube defect prevention: application of model}

Neural tube defects are a complex group of birth defects that do not share a single cause and not all are preventable with adequate folic acid intake. ${ }^{12}$ Distributions of red blood cell folate concentration predict only the risk of neural tube defects that are folate sensitive and amenable to prevention by folic acid; if the associations presented here are accurate, distributions of red blood cell folate concentrations should predict risk of neural tube defects independently of other causes of neural tube defects. Periconceptional folic acid supplementation and food fortification programs have been observed to reduce the prevalence of neural tube defects by about $30-80 \%$, depending on several factors such as the level of folic acid fortification and background prevalence of neural tube defects. ${ }^{1-3-9} 27$ Overall, a prevalence of neural tube defects lower than 5-6 per 10000 births has not been achieved consistently during intervention studies or after folic acid fortification, ${ }^{1-3}$ 5-9 27 so we might reasonably assume that the lowest feasible prevalence of neural tube defects obtainable through folic acid based interventions is approximately 5-6 per 10000 births.

\section{Implications for United States}

Before fortification of food with folic acid (1995-96), the prevalence of neural tube defects in the United States was estimated to be 10.8 per 10000 births (fig $4 \Downarrow$ )..$^{39}$ Applying the estimated risk model presented here to published adjusted NHANES red blood cell folate concentrations, we estimate a predicted median pre-fortification (1988-94 women and girls aged $>4$ years) prevalence of neural tube defects of $13(95 \%$ uncertainty interval 10.1 to 16.4$)$ per 10000 births. Parker and colleagues (2010) reported a post-fortification (2004-06) prevalence of 6.8 neural tube defects per 10000 births in active surveillance programs (2.23 (95\% confidence interval 2.07 to 2.41) per 10000 for anencephaly, 3.72 (3.52 to 3.94) for spina bifida without anencephaly, and 0.84 (0.74 to 0.94 ) for encephalocele) ${ }^{39}{ }^{40}$ Using the published adjusted NHANES distributions of red blood cell folate concentration, ${ }^{33}{ }^{35}$ and the risk model developed in this analysis, we estimated a median post-fortification (2005-10, women and girls aged $>4$ years) prevalence of 5.9 (95\% uncertainty interval 4.2 to 7.8 ) neural tube defects per 10000 births. Our overall prevalence estimates for neural tube defects (fig $4 \Downarrow$ ) are therefore consistent with the estimates in the published literature based on US surveillance systems before and after fortification. ${ }^{39}{ }^{40}$ Pre-fortification, the 10 th centile of women had a substantially increased risk of neural tube defect ( 25 neural tube defects per 10000$)$ and the 50 th centile of the folate concentration distribution among all US women was below the likely optimal blood folate 
concentration range of $1000-1300 \mathrm{nmol} / \mathrm{L}$; post-fortification, all but the 10th centile of all pregnant women in their first trimester were at or above the estimated optimal range (supplementary table G).

Additional studies are needed to characterize the portion of US women of reproductive age with insufficient red blood cell folate concentration and to determine whether they would benefit from additional folate/folic acid intake. Encouragingly for US prevention efforts in the post-folic acid fortification era, a large percentage of pregnant US women have red blood cell folate concentrations at or above those associated with low risk of neural tube defects, even in the absence of folic acid supplement use. Given the high rate of unplanned pregnancies in the United States $(\sim 50 \%),{ }^{41}$ the fact that the neural tube closes by day 28 of gestation (often before a woman confirms that she is pregnant), and the low levels of supplement use among women of childbearing age $(\sim 32 \%),{ }^{42}$ a subset of non-supplement using women might still be at increased risk of folate preventable neural tube defects (supplementary table G).

\section{Implications for other countries}

The low rates of compliance with recommendations on folic acid supplementation have also been documented in many non-US populations. ${ }^{43-46}$ A recent study of more than 400000 women in the United Kingdom found that only $31 \%$ of women overall and $51 \%$ of women with a previous neural tube defect affected pregnancy consumed a folic acid supplement before their current pregnancy. ${ }^{43}$ This low rate of compliance with recommendations even among those at high risk is concerning given the lack of mandatory folic acid fortification in the United Kingdom. The model presented here shows that modest shifts in red blood cell folate concentrations among those with the lowest concentrations produce the greatest reduction in risk of neural tube defect. We estimate that the risk of neural tube defects in the fifth centile of red blood cell folate concentrations among all US women dropped considerably from a pre-fortification (1988-94) estimated 35.9 (95\% uncertainty interval 28.1 to 46.2$)$ neural tube defects per 10000 births to a post-fortification (2005-10) 14.6 (12.4 to17.0) neural tube defects per 10000 births with a moderate $300 \mathrm{nmol} / \mathrm{L}$ increase in blood folate concentration. This suggests that food fortification programs that reach the most at risk populations with a moderate intake of folic acid have the best potential for impact on the prevalence of neural tube defects, especially in settings with low compliance with recommendations on pre-pregnancy folic acid supplementation.

\section{Unanswered questions and future research Folic acid intake}

How much natural food folate and/or folic acid intake is necessary to achieve red blood cell folate concentrations in the $1000-1300 \mathrm{nmol} / \mathrm{L}$ range in any given person or population is unknown. In the Folic Acid Dosing Trial in northern China, ${ }^{154}$ people consuming $100 \mu \mathrm{g} /$ day in addition to usual diet (which is relatively low in other sources of folate) did not achieve a red blood cell folate concentration of $1000 \mathrm{nmol} / \mathrm{L}$ by the end of the six month supplementation trial. ${ }^{24}$ Those with the CC and CT genotypes who consumed $400 \mu \mathrm{g} / \mathrm{day}$ reached a red blood cell folate concentration of $1000 \mathrm{nmol} / \mathrm{L}$ between three and six months of supplementation, whereas those with the TT genotype did not achieve a geometric mean red blood cell folate concentration of $1000 \mathrm{nmol} / \mathrm{L}$ by the six month sample. ${ }^{24}$ However, the geometric mean red blood cell folate concentration of the MTHFR TT group did surpass the $906 \mathrm{nmol} / \mathrm{L}$ threshold used by Daly et al, ${ }^{28}$ and it continued to rise after six months of supplementation. Other studies of folic acid supplementation at $400 \mu \mathrm{g} /$ day dosage have found that red blood cell folate concentrations reached $1000 \mathrm{nmol} / \mathrm{L}$ after approximately two to six months of supplementation depending on baseline concentrations among other factors (supplementary figure $\mathrm{F}$ ). ${ }^{16-23}$ A recent study showed that a steady state of red blood cell folate concentrations was not achieved until after 12 months of supplementation ( $1 \mathrm{mg} /$ day dose in older adults), and whether a steady state is reached sooner or later for lower folic acid dosages is unclear. ${ }^{47}$ The red blood cell folate concentration associated with a $1000 \mu \mathrm{g} /$ day dose for 12-24 months was between 3010 and $3430 \mathrm{nmol} / \mathrm{L}$ in New Zealand participants aged 65 years and older. ${ }^{47}$ In the United States, the median folic acid intake from enriched cereal grain product (fortification) has been estimated to be $138 \mu \mathrm{g} /$ day and that from both enriched cereal grain product and ready to eat cereal to be $274 \mu \mathrm{g} / \mathrm{day}{ }^{48}$ Pregnant non-supplement users might consume an amount of folic acid similar to that of the general population, which would contribute to the observed elevated red blood cell folate concentrations and the observed reductions in neural tube defects after fortification. ${ }^{34}$ In determining how much folate and/or folic acid needs to be consumed to reach a red blood cell folate concentration in the "optimal" range, determining the baseline folate concentrations, the length of time before neural tube closure, and MTHFR genotype, among other factors, will be important. If supplementation is started more than six months before pregnancy or folic acid is ingested regularly as part of food fortification, these data suggest that a folic acid dosage of less than $400 \mu \mathrm{g} /$ day (but greater than $100 \mu \mathrm{g} /$ day) in addition to a usual diet could be sufficient to prevent most folate sensitive neural tube defects in many populations of women.

Determination of the range of natural food folate and/or folic acid necessary to achieve any proposed optimal concentration in different populations is a subject for future research projects. We are unaware of any adverse outcomes associated with the moderate red blood cell folate concentrations in the proposed optimal range ( $1000-1300 \mathrm{nmol} / \mathrm{L})$. The modeled associations presented here provide evidence that red blood cell folate concentrations in excess of $1300-1500 \mathrm{nmol} / \mathrm{L}$ provide little additional benefit for prevention of neural tube defects, so substantial benefit in reducing risk of neural tube defect might be achieved by folic acid intakes well below the $1000 \mu \mathrm{g} / \mathrm{day}$ tolerable upper intake level.

\section{Other populations}

Information about folate status, neural tube defect rates, and changes in red blood cell folate concentration in response to folic acid intake in many regions of the world is very limited, especially in African countries. Although the associations between risk of neural tube defect and red blood cell folate concentrations are remarkably similar between these Irish, Chinese, and overall US (majority of European decent) populations, whether they also apply to other populations is not known.

\section{Plasma or serum folate concentrations}

Many researchers measure serum or plasma folate concentrations to monitor folate status. Unfortunately, Daly et al report that they did not present a plasma folate concentration model owing to the fact that plasma folate is a very short term measure of blood folate concentration, and red blood cell folate concentrations (collected at 15 weeks' gestation) were considered to be most similar to those to which the fetus was exposed. ${ }^{28}$ Women with plasma folate concentrations above 
$15.9 \mathrm{nmol} / \mathrm{L}$ had an associated risk of $9(95 \%$ confidence interval 5 to 17$)$ neural tube defects per $10000 .{ }^{28}$ In the United States after fortification, the 25 th centile of women had serum folate concentrations of $29.5 \mathrm{nmol} / \mathrm{L}$, and the 50th centile had serum folate concentration of $43.5 \mathrm{nmol} / \mathrm{L}$ (2005-10 NHANES $>4$ years of age, serum folate concentrations unadjusted for assay difference; 25 th and 50th centile red blood cell folate concentrations 1050 and $1379 \mathrm{nmol} / \mathrm{L}$, respectively, adjusted for assay difference; supplementary table F). ${ }^{33}$ Additional research is needed to explore the utility of using plasma or serum folate concentrations to predict the risk of neural tube defects and to monitor prevention programs.

\section{Conclusions}

We provide evidence that red blood cell folate concentration is a generalizable marker for risk of neural tube defects and that setting "optimal" or target population red blood cell folate concentrations will be useful in assessing the need for and monitoring the success of programs for the prevention of folate sensitive neural tube defects. Our results indicate that risk of neural tube defects is substantially attenuated in populations with higher red blood cell folate concentrations.

We thank Christine Pfeiffer for providing equations to convert between subtypes of microbiologic folate assays.

Contributions: KSC conceived the study and drafted the manuscript. OD designed and performed the statistical analysis and drafted the statistical methods. OD and KSC generated figures and tables. RJB and $\mathrm{LH}$ contributed to the design and execution of the Folic Acid Dosing Study. RJB, SL, and ZL contributed to the design and execution of the Community Intervention Project. LH and JZ did laboratory testing and laboratory data analysis. AMM collected and provided data from the Irish study. KSC, OD, NFD, AMM, LH, and RBJ contributed to the study design. KSC, OD, LH, NFD, SL, AMM, ZL, JZ, and RBJ contributed to data interpretation and provided critical review of the manuscript. KSC is the guarantor.

Competing interests: All authors have completed the ICMJE uniform disclosure form at www.icmje.org/coi_disclosure.pdf (available on request from the corresponding author) and declare: no support from any organization for the submitted work; no financial relationships with any organizations that might have an interest in the submitted work in the previous three years; no other relationships or activities that could appear to have influenced the submitted work.

Ethical approval: The Community Intervention Project was approved by the Centers for Disease Control and Prevention Institutional Review Board and the Ethical Committee of the Beijing Medical University (IRB00000185; IRB00008166). Informed consent was obtained for the Folic Acid Dosing Trial, and the study was approved by the Centers for Disease Control and Prevention Institutional Review Board and the Ethical Committee on Biomedical Research Involving Human Subjects of the Health Science Center, Peking University (IRB00000185;

IRB00008166) (including a waiver for the documentation of informed consent as set forth in 45CFR46.117(c))

Funding: Funding for salaries of CDC employees was provided by the Centers for Disease Control and Prevention. No specific funding was provided for this project. The findings and conclusions in this report are those of the authors and do not necessarily represent the official position of the Centers for Disease Control and Prevention.

Transparency statement: The lead author (the manuscript's guarantor) affirms that the manuscript is an honest, accurate, and transparent account of the study being reported; that no important aspects of the study have been omitted; and that any discrepancies from the study as planned have been explained.
Data sharing: Model parameters and priors are given in the statistical appendix in the supplementary materials. No additional data are available.

1 Berry RJ, Li Z, Erickson JD, Li S, Moore CA, Wang H, et al. Prevention of neural-tube defects with folic acid in China: China-U.S. Collaborative Project for Neural Tube Defect Prevention. N Engl J Med 1999;341:1485-90.

2 MRC Vitamin Study Research Group. Prevention of neural tube defects: results of the Medical Research Council Vitamin Study. Lancet 1991;338:131-7.

3 Czeizel AE, Dudas I. Prevention of the first occurrence of neural-tube defects by periconceptional vitamin supplementation. N Engl J Med 1992;327:1832-5.

4 Shibuya K, Murray CJL. Congenital anomalies. In: Murray CJ, Lopez AD, eds. Health dimensions of sex and reproduction. Harvard School of Public Health on behalf of the World Health Organization and the World Bank, 1998:455-512.

5 Cortes F, Mellado C, Pardo RA, Villarroel LA, Hertrampf E. Wheat flour fortification with folic acid: changes in neural tube defects rates in Chile. Am J Med Genet $A$ 2012;158:1885-90

6 De Wals P, Tairou F, Van Allen MI, Lowry RB, Evans JA, Van den Hof MC, et al. Spina bifida before and after folic acid fortification in Canada. Birth Defects Res A Clin Mol Teratol 2008;82:622-6.

7 Chen LT, Rivera MA. The Costa Rican experience: reduction of neural tube defects following food fortification programs. Nutr Rev 2004;62:S40-3.

8 Williams LJ, Mai CT, Edmonds LD, Shaw GM, Kirby RS, Hobbs CA, et al. Prevalence of spina bifida and anencephaly during the transition to mandatory folic acid fortification in the United States. Teratology 2002;66:33-9.

9 Sayed AR, Bourne D, Pattinson R, Nixon J, Henderson B. Decline in the prevalence of neural tube defects following folic acid fortification and its cost-benefit in South Africa. Birth Defects Res A Clin Mol Teratol 2008;82:211-6.

10 Folic acid for the prevention of neural tube defects: U.S. Preventive Services Task Force recommendation statement. Ann Intern Med 2009;150:626-31.

11 Selhub J, Jacques PF, Dallal G, Choumenkovitch S, Rogers G. The use of blood concentrations of vitamins and their respective functional indicators to define folate and vitamin B12 status. Food Nutr Bull 2008;29(2 suppl):S67-73.

12 Wallingford JB, Niswander LA, Shaw GM, Finnell RH. The continuing challenge of understanding, preventing, and treating neural tube defects. Science 2013;339:1222002.

13 McMahon DM, Liu J, Zhang H, Torres ME, Best RG. Maternal obesity, folate intake, and neural tube defects in offspring. Birth Defects Res A Clin Mol Teratol 2013;97:115-22.

14 Agopian AJ, Tinker SC, Lupo PJ, Canfield MA, Mitchell LE, for the National Birth Defects Prevention Study. Proportion of neural tube defects attributable to known risk factors. Birth Defects Res A Clin Mol Teratol 2013;97:42-6.

15 Hao L, Yang Q-H, Li Z, Bailey LB, Zhu J-H, Hu DJ, et al. Folate status and homocysteine response to folic acid doses and withdrawal among young Chinese women in a large-scale randomized double-blind trial. Am J Clin Nutr 2008:88:448-57.

16 Cuskelly GJ, McNulty H, Scott JM. Fortification with low amounts of folic acid makes a significant difference in folate status in young women: implications for the prevention of neural tube defects. Am J Clin Nutr 1999;70:234-9.

17 Lamers Y, Prinz-Langenohl R, Bramswig S, Pietrzik K. Red blood cell folate concentrations increase more after supplementation with [6S]-5-methyltetrahydrofolate than with folic acid in women of childbearing age. Am J Clin Nutr 2006;84:156-61.

18 Hursthouse NA, Gray AR, Miller JC, Rose MC, Houghton LA. Folate status of reproductive age women and neural tube defect risk: the effect of long-term folic acid supplementation at doses of 140 microg and 400 microg per day. Nutrients 2011;3:49-62.

19 Norsworthy B, Skeaff CM, Adank C, Green TJ. Effects of once-a-week or daily folic acid supplementation on red blood cell folate concentrations in women. Eur $\mathrm{J}$ Clin Nutr 2004;58:548-54.

20 Green TJ, Skeaff CM, Rockell JE, Venn BJ. Folic acid fortified milk increases blood folate and lowers homocysteine concentration in women of childbearing age. Asia Pac J Clin Nutr 2005;14:173-8

21 Adank C, Green TJ, Skeaff CM, Briars B. Weekly high-dose folic acid supplementation is effective in lowering serum homocysteine concentrations in women. Ann Nutr Metab 2003;47:55-9.

22 Daly S, Mills JL, Molloy AM, Conley M, Lee YJ, Kirke PN, et al. Minimum effective dose of folic acid for food fortification to prevent neural-tube defects. Lancet 1997;350:1666-9.

23 Schorah CJ, Wild J, Hartley R, Sheppard S, Smithells RW. The effect of periconceptional supplementation on blood vitamin concentrations in women at recurrence risk for neural tube defect. Br J Nutr 1983;49:203-11.

24 Crider KS, Zhu JH, Hao L, Yang QH, Yang TP, Gindler J, et al. MTHFR 677C->T genotype is associated with folate and homocysteine concentrations in a large, population-based, double-blind trial of folic acid supplementation. Am J Clin Nutr 2011;93:1365-72.

25 Yan L, Zhao L, Long Y, Zou P, Ji G, Gu A, et al. Association of the maternal MTHFR C677T polymorphism with susceptibility to neural tube defects in offsprings: evidence from 25 case-control studies. PloS One 2012;7:e41689.

26 Zhang T, Lou J, Zhong R, Wu J, Zou L, Sun Y, et al. Genetic variants in the folate pathway and the risk of neural tube defects: a meta-analysis of the published literature. PloS One 2013;8:e59570.

27 De Wals P, Tairou F, Van Allen MI, Un SH, Lowry RB, Sibbald B, et al. Reduction in neural-tube defects after folic acid fortification in Canada. N Engl J Med 2007;357:135-42.

28 Daly LE, Kirke PN, Molloy A, Weir DG, Scott JM. Folate levels and neural tube defects: implications for prevention. JAMA 1995;274:1698-702.

29 Hao L, Ma J, Stampfer MJ, Ren A, Tian Y, Tang Y, et al. Geographical, seasonal and gender differences in folate status among Chinese adults. J Nutr 2003;133:3630-35.

30 Mao R, Fan Y, Chen F, Sun D, Bai J, Fu S. Methylenetetrahydrofolate reductase gene polymorphisms in 13 Chinese ethnic populations. Cell Biochem Funct 2008;26:352-8.

31 Wilcken B, Bamforth F, Li Z, Zhu H, Ritvanen A, Renlund M, et al. Geographical and ethnic variation of the $677 \mathrm{C}>\mathrm{T}$ allele of 5,10 methylenetetrahydrofolate reductase (MTHFR) findings from over 7000 newborns from 16 areas world wide. J Med Genet 2003:40:619-25.

32 O'Broin S, Kelleher B. Microbiological assay on microtitre plates of folate in serum and red cells. J Clin Pathol 1992;45:344-7.

33 Pfeiffer CM, Hughes JP, Lacher DA, Bailey RL, Berry RJ, Zhang M, et al. Estimation of trends in serum and RBC folate in the U.S. population from pre- to postfortification using assay-adjusted data from the NHANES 1988-2010. J Nutr 2012;142:886-93.

34 Branum AM, Bailey R, Singer BJ. Dietary supplement use and folate status during pregnancy in the United States. J Nutr 2013;143:486-92. 


\section{What is already known on this topic}

If taken regularly before pregnancy, $400 \mu \mathrm{g} /$ day of folic acid reduces a woman's risk of a neural tube defect affected pregnancy by up to $85 \%$

Increased intake of folate and/or folic acid increases red blood cell (RBC) folate concentrations, so these might be a reasonable biomarker for risk of neural tube defects in the establishment and monitoring of prevention programs

A study in an Irish population showed that the risk of a neural tube defect affected pregnancy increased 10-fold as RBC folate concentrations decreased

\section{What this study adds}

A generalizable dose-response relation exists between RBC folate concentrations and risk of neural tube defects in both Irish and Chinese women despite differences in genetic background and diet

$\mathrm{RBC}$ folate concentration distributions alone can be used to predict prevalence of neural tube defects and change in prevalence associated with folic acid food fortification

RBC folate concentrations above about $1000 \mathrm{nmol} / \mathrm{L}$ are consistent with optimal reduction in risk of folate sensitive neural tube defects but limited additional risk reductions are predicted with concentrations above about $1300 \mathrm{nmol} / \mathrm{L}$

35 Pfeiffer CM, Zhang M, Lacher DA, Molloy AM, Tamura T, Yetley EA, et al. Comparison of serum and red blood cell folate microbiologic assays for national population surveys. $J$ Nutr 2011:141:1402-9.

36 Holmes MV, Newcombe P, Hubacek JA, Sofat R, Ricketts SL, Cooper J, et al. Effect modification by population dietary folate on the association between MTHFR genotype, homocysteine, and stroke risk: a meta-analysis of genetic studies and randomised trials. Lancet 2011;378:584-94.

37 Milman N, Byg KE, Hvas AM, Bergholt T, Eriksen L. Erythrocyte folate, plasma folate and plasma homocysteine during normal pregnancy and postpartum: a longitudinal study comprising 404 Danish women. Eur J Haematol 2006;76:200-5.

38 Ubeda N, Reyes L, Gonzalez-Medina A, Alonso-Aperte E, Varela-Moreiras G. Physiologic changes in homocysteine metabolism in pregnancy: a longitudinal study in Spain. Nutrition 2011;27:925-30

39 Centers for Disease Control and Prevention (CDC). CDC Grand Rounds: additional opportunities to prevent neural tube defects with folic acid fortification. MMWR Morb Mortal Wkly Rep 2010;59:980-4.

40 Parker SE, Mai CT, Canfield MA, Rickard R, Wang Y, Meyer RE, et al. Updated nationa birth prevalence estimates for selected birth defects in the United States, 2004-2006. Birth Defects Res A Clin Mol Teratol 2010;88:1008-16.

41 Finer LB, Zolna MR. Unintended pregnancy in the United States: incidence and disparities, 2006. Contraception $2011 ; 84: 478-85$

42 Tinker SC, Cogswell ME, Devine O, Berry RJ. Folic acid intake among U.S. women aged 15-44 years, National Health and Nutrition Examination Survey, 2003-2006. Am J Prev Med 2010;38:534-42.

43 Bestwick JP, Huttly WJ, Morris JK, Wald NJ. Prevention of neural tube defects: a cross-sectional study of the uptake of folic acid supplementation in nearly half a million women. PloS One 2014:9:e89354.
44 Nelson CR, Leon JA, Evans J. The relationship between awareness and supplementation: which Canadian women know about folic acid and how does that translate into use? Can J Public Health 2014;105:e40-6.

45 McDonnell R, Delany V O'Mahony MT, Mullaney C, Lee B, Turner MJ Neural tube defects in the Republic of Ireland in 2009-11. J Public Health (Oxf) 2014; published online 18 March.

46 Horn F, Sabova L, Pinterova E, Hornova J, Trnka J. Prevention of neural tube defects by folic acid-awareness among women of childbearing age in Slovakia. Bratisl Lek Listy 2014;115:91-7.

47 Bradbury KE, Williams SM, Green TJ, McMahon JA, Mann JI, Knight RG, et al. Differences in erythrocyte folate concentrations in older adults reached steady-state within one year in a two-year, controlled, $1 \mathrm{mg} / \mathrm{d}$ folate supplementation trial. J Nutr 2012;142:1633-7.

48 Yang Q, Cogswell ME, Hamner HC, Carriquiry A, Bailey LB, Pfeiffer CM, et al. Folic acid source, usual intake, and folate and vitamin B-12 status in US adults: National Health and Nutrition Examination Survey (NHANES) 2003-2006. Am J Clin Nutr 2010;91:64-72.

\section{Accepted: 23 June 2014}

\section{Cite this as: BMJ 2014;349:g4554}

This is an Open Access article distributed in accordance with the Creative Commons Attribution Non Commercial (CC BY-NC 3.0) license, which permits others to distribute, remix, adapt, build upon this work non-commercially, and license their derivative works on different terms, provided the original work is properly cited and the use is non-commercial. See: http://creativecommons.org/licenses/by-nc/3.0/. 


\section{Tables}

Table 1| Estimated red blood cell folate concentrations associated with specified levels of risk of neural tube defect among participants in Community Intervention Project

\begin{tabular}{|c|c|c|}
\hline Neural tube defect risk per 10000 births & Red blood cell folate concentration ( $\mathrm{nmol} / \mathrm{L})^{\star}$ & $95 \%$ uncertainty interval $\dagger$ \\
\hline 40 & 380 & 320 to 449 \\
\hline 20 & 580 & 510 to 640 \\
\hline 10 & 870 & 790 to 960 \\
\hline 6 & 1180 & 1050 to 1340 \\
\hline 5 & 1310 & 1150 to 1520 \\
\hline
\end{tabular}

Estimates were derived using estimated parameters of neural tube defect risk model; details on model, underlying assumptions, and methods used to develop estimates are provided in supplementary material.

*Median (rounded to nearest 10) of posterior distribution for possible values of red blood cell folate concentration associated with specified level of neural tube defect risk.

tLower value of this interval is 2.5 th centile of posterior distribution for possible values of red blood cell folate concentration associated with specified level of neural tube defect risk; upper value is 97.5 th centile of distribution. 
Table 2| Estimated risk of neural tube defect per 10000 births for specified red blood cell folate concentrations among participants in Community Intervention Project

\begin{tabular}{|c|c|c|}
\hline Red blood cell folate concentration ( $\mathrm{nmol} / \mathrm{L}$ ) & Neural tube defect risk per 10000 births* & $95 \%$ uncertainty interval $†$ \\
\hline 340 & 48.8 & 36.2 to 65.6 \\
\hline 500 & 25.4 & 20.8 to 31.2 \\
\hline 700 & 14.4 & 12.2 to 16.8 \\
\hline 800 & 11.5 & 9.8 to 13.4 \\
\hline 900 & 9.4 & 7.9 to 11.0 \\
\hline 1000 & 7.9 & 6.5 to 9.3 \\
\hline 1100 & 6.7 & 5.5 to 8.1 \\
\hline 1200 & 5.8 & 4.6 to 7.1 \\
\hline 1300 & 5.1 & 4.0 to 6.3 \\
\hline 1400 & 4.5 & 3.4 to 5.6 \\
\hline
\end{tabular}

Estimates were derived using estimated parameters of neural tube defect risk model; details on model, underlying assumptions, and methods used to develop estimates are provided in supplementary material.

*Median of posterior distribution of possible values for neural tube defect risk associated with specified red blood cell folate concentration.

†Lower value of interval is 2.5 th centile of posterior distribution for possible values of neural tube defect risk associated with specified red blood cell folate concentration; upper value is 97.5 th centile of distribution. 


\section{Figures}

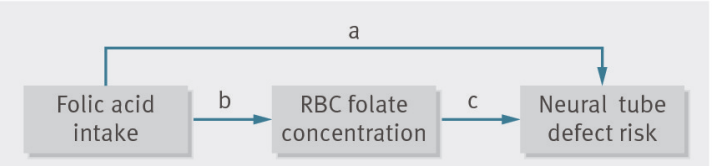

Fig 1 Relation between folic acid intake, blood folate concentration, and risk of neural tube defects. a: Many studies have shown that folic acid intake from multivitamin and folic acid only supplements (common doses between 200 and 5000 $\mu \mathrm{g} / \mathrm{day}$ ) in the periconceptional period (before neural tube closure at day 28) reduces risk of neural tube defects in those pregnancies. b: Controlled folic acid intake studies show that folic acid increases blood folate concentrations; these studies have shown that absolute concentration after folic acid intake is dependent on dose of folic acid supplements, length of time supplement is consumed, baseline folate concentration, and genetic variation in folate metabolism (notably MTHFR677). c: Single study of blood folate concentration (red blood cell (RBC) and plasma) during pregnancy (mean gestational age 15 weeks) showed inverse dose-response with risk of neural tube defects in offspring. Study reported here used information from existing data sources to build a statistical model to predict association between RBC folate concentration at time of neural tube closure (embryologic day 28 ) and risk of neural tube defects

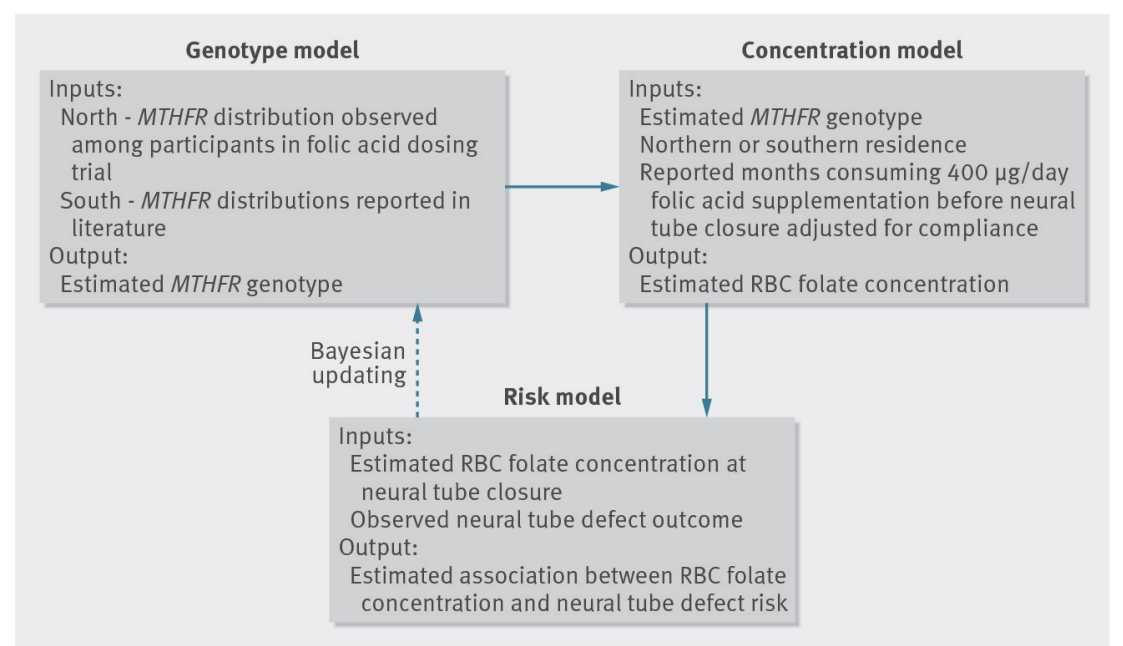

Fig 2 Genotype, concentration, and risk model components used to assess association between red blood cell (RBC) folate concentration and risk of neural tube defects among Community Intervention Project participants. Genotype model: MTHFR genotype frequencies have been shown to be different in northern (36\% TT in Folic Acid Dosing Trial) and southern Chinese populations (8\% TT). ${ }^{202526}$ Each person was assigned a probability of having a specific genotype. RBC folate concentration model: RBC folate concentration at time of neural tube closure was estimated on basis of region of residence (northern $v$ southern), probable genotype, and folic acid supplementation history. Substantial regional differences in diet have been previously described, with northern regions having less natural folate intake and lower RBC folate concentrations. ${ }^{129-31}$ As a result, the concentration model included a term reflecting regional differences in baseline RBC concentration. Neural tube defect risk model: risk of neural tube defects associated with RBC folate concentrations was estimated for Community Intervention Project participants on basis of observed neural tube defect occurrence and estimated RBC folate concentration 


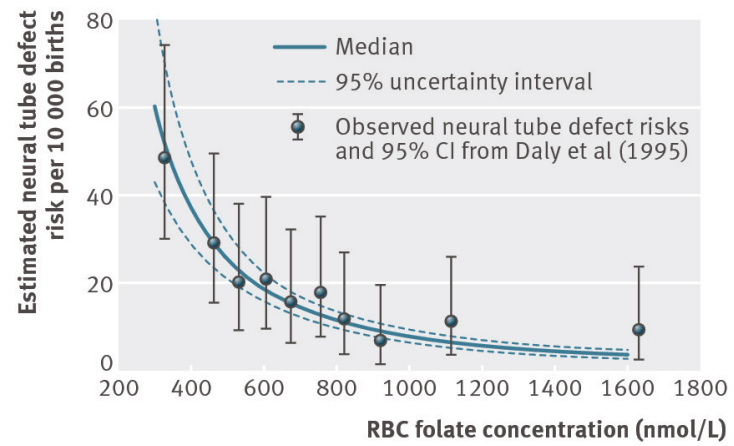

Fig 3 Estimated risk of neural tube defect per 10000 births by red blood cell (RBC) folate concentration (nmol/L) at time of neural tube closure among participants in Community Intervention Project and observed values of neural tube defect risk at measured RBC folate concentrations ( $\mathrm{nmol} / \mathrm{L}$ ) reported by Daly et al (1995). Estimates were derived using estimated parameters of neural tube defect risk model to predict neural tube defect risk at specified RBC folate concentrations. Solid blue line is median of posterior distribution of possible values of neural tube defect risk at given concentration; dashed blue lines reflect $95 \%$ uncertainty interval for estimate. Lower value of this interval is 2.5 th centile of posterior distribution of possible values for neural tube defect risk; upper value is 97.5 th centile. Estimated time of closure of fetal neural tube was date of initiation of last reported menstrual cycle plus 42 days

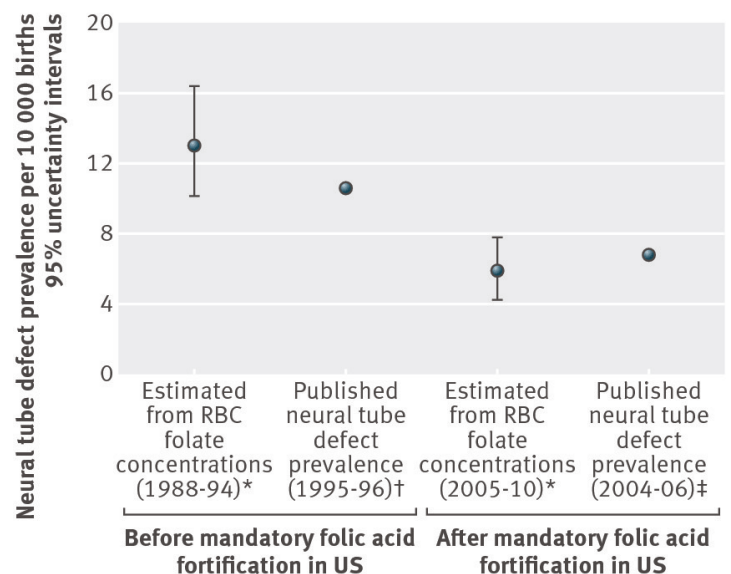

Fig 4 Using model developed with Chinese data to predict prevalence of neural tube defects from population level red blood cell (RBC) folate concentrations in US population before and after mandatory folic acid fortification. * RBC folate concentrations from Pfeiffer et $\mathrm{al}^{33}$ (supplementary table D, female participants 4 years and older during pre-fortification period, NHANES 1988-94; supplementary table F, total female participants aged 4 years and older, NHANES 2005-10). Published RBC folate concentration centiles were normalized to method used in papers by both Daly and Hao, using standardizing equations generated from Pfeiffer 201135: NHANES RBC folate $(\mathrm{nmol} / \mathrm{L})=($ Dublin RBC folate $(\mathrm{nmol} / \mathrm{L}) \times 0.7876)+34.2802(\mathrm{nmol} / \mathrm{L})$ (personal communication). These adjusted RBC folate concentrations were used to generate a modeled population with a similar distribution of RBC folate concentration; modeled associations in Chinese data were then used to predict risk in that modeled US population. †Neural tube defect prevalence for US (1994-95) just before start of mandatory folic acid fortification. ${ }^{39}$ $\ddagger$ Neural tube defect prevalence for US (2004-06) after implementation of mandatory folic acid fortification ${ }^{40}$ 